\title{
Ecuador's Yasuní-ITT Initiative: A Case Study on International Climate Change Mitigation Narratives
}

\author{
Mairin Peck, Clark Honors College*
}

\begin{abstract}
In 2007, Ecuador's president Rafael Correa presented an audacious climate change mitigation plan to the world: Ecuador would leave 846 million barrels of crude oil untouched beneath the Amazon if the global community reciprocated with a contribution of 3.6 billion dollars - half of the oil's market value (McAvoy 27). The Yasuni-ITT Initiative, named after the area it sought to save, vowed to preserve immense biodiversity, protect indigenous groups, and prevent the emission of 410 million tons of carbon dioxide (Permanent Forum on Indigenous Issues). In 2013, Correa abandoned the initiative, lamenting the lack of international support, and approved oil drilling in the Yasuní (Correa, "Anuncio a la Nación" 3). The purpose of this investigation was to identify and examine the various narratives employed in the Yasuni-ITT Initiative, with the hope of discovering transferrable conclusions for other global mitigation efforts. This project relied heavily on speeches, government documents, and media accounts in both English and Spanish to identify common narratives, while secondary scholarly articles were used to frame the analysis. The narratives deployed in Ecuador's Yasuní-ITT Initiative common but unequal responsibility for climate change, a reconceptualization of value, and Ecuador as martyr and revolutionary - reflect a framework that simultaneously criticized and sought authority from the capitalist ideal. The failure of the Yasuni-ITT Initiative to capture the hearts and wallets of the world provides insight into the dominant global forces and perspectives on climate change mitigation policy.
\end{abstract}

\section{INTRODUCTION}

The Intergovernmental Panel on Climate Change (IPCC) defines mitigation as "the effort to control the human sources of climate change and their cumulative impacts, notably the emissions of greenhouse gases" (Intergovernmental Panel on Climate Change 114). Mitigation efforts ranging in scale from local to international encounter obstacles related to prioritization, economics, technological capacity, and political tensions (IPCC 137). Internationally coordinated attempts to reduce emissions arguably experience these challenges most acutely. Consequentially, global policies and agreements that have the greatest power to effect change are also the most

\footnotetext{
*Mairin Peck is a senior in the University of Oregon Clark Honors College majoring in Human Physiology and Spanish. Her varied academic interests have landed her in Querétaro, México on a study abroad program and in a research lab at the UO investigating exercise and environmental physiology. Outside of academia, Mairin competes in triathlons as a member of the UO's club team. Two years after entering the sport, she is the current USA Triathlon Northwest Collegiate Conference Champion. Mairin is also an aspiring world traveler - she has spent time in Central and South America and is planning an extended trip after graduation. Please direct all correspondence to mairinp@gmail.com.
} 
difficult to develop and implement. The United Nations Framework Convention on Climate Change (UNFCCC) was established in 1992 to navigate this challenging process, but its achievements have been limited. Given the rapid and often disastrous climate change occurring worldwide, innovative and impactful mitigation strategies are desperately needed. Ecuador's 2007 Yasuní-ITT Initiative, examined as a case study in global mitigation, offers valuable insight into the dominant forces and perspectives that dictate such internationally coordinated mitigation efforts.

In 2007, Ecuador's president Rafael Correa presented the Yasuní-ITT Initiative to the United Nations (UN). The initiative pledged to leave 846 million barrels of crude oil untouched in the Isphingo, Tambococha, and Tiputini oilfields (ITT) located within Yasuní National Park. In exchange, Correa asked for $\$ 3.6$ billion in global contributions, half of the oil's 2007 market value (Espinosa 27). The proposal anticipated three benefits. First, the initiative vowed to protect two indigenous groups living in voluntary isolation in Yasuní National Park (Permanent Forum). Second, the proposal sought to preserve immense biodiversity within the park - a UNESCO World Biosphere Reserve home to 600 bird species and more tree species than all of the United States and Canada combined (Permanent Forum; McAvoy 27). Third, the plan pledged to prevent the emission of 407 million tons of carbon dioxide emissions from the burning of fossil fuels (Permanent Forum). While the UN and many powerful individuals lauded the plan, supporters of the oil industry and many media outlets characterized it as "rain forest for ransom" (Achtenberg; Walsh). Ultimately, the Yasuní-ITT Initiative did not receive the global financial support it sought, and in 2013 Correa abandoned the proposal and approved oil drilling in Yasuní National Park (Correa, “Anuncio a la Nación” 7).

This analysis identifies and examines the principal environmental narratives employed in the Yasuní-ITT Initiative by Rafael Correa and his government. Environmental narratives are often referenced in scholarly discourse on climate change, but a clear definition of "environmental narrative" is rarely offered. One definition, proposed in a 1996 book titled The Lie of the Land, is a "convenient yet simplistic belief about the nature, causes and impacts of environmental problems, which also influences the generation of further environmental research and proposed solutions" (Forsyth 3). While this definition encompasses many aspects of current environmental narratives, the content and form of contemporary narratives are extremely varied. In this analysis, the term "narrative" loosely describes the discourse and strategies used to present the YasuníITT Initiative to the global community. The narratives often drew on established environmental concepts, and also introduced complex and controversial perspectives to the international discussion.

Narratives were identified by examining Correa's speeches and other government documents, and primary narratives were selected based on their importance to the overall framing of the initiative. Research was conducted in both Spanish and English, but Spanish sources have been translated to English for inclusion in this analysis. The principal narratives identified are: common but differentiated responsibility for climate change, a reconceptualization of value, and Ecuador as martyr and revolutionary. These were not the only narratives deployed during the six- 
year campaign, but they were the most enduring and fundamental. Further, these narratives were not static; in fact, the way in which they evolved is an important element of this analysis.

The limitations of the current study should be recognized. While this analysis accurately represented the narratives present in the Yasuní-ITT Initiative as advanced by Rafael Correa and his government, it did not attempt to address the complexities surrounding the initiative. Myriad other factors, including political tensions and economic situations, played into the initiative's defeat. Further, responses to the initiative - both locally and globally - ranged from effusive praise to passionate dissent. This analysis deliberately avoids evaluating the merits of the initiative. Instead, the goal is to objectively examine the principal narratives employed in the six year Yasuní-ITT campaign with the hope of encountering transferrable lessons for other global climate change mitigation attempts.

The narratives utilized in Ecuador's Yasuní-ITT Initiative - common but differentiated responsibility for climate change, a reconceptualization of value, and Ecuador as martyr and revolutionary - challenged capitalist ideals of value and self-interest, although the initiative itself worked loosely within the capitalist system. As a case study in global climate change, the initiative confirms the seemingly inevitable and requisite role of capitalist inspired market solutions. This analysis proposes that the unique narratives advanced in the Yasuní-ITT Initiative, though proven ineffective in garnering global support, are perhaps better suited to small scale, local proposals.

\section{COMMON BUT DIFFERENTIATED RESPONSIBILITY}

The Yasuní-ITT Initiative was founded on the concept of common but differentiated responsibility (CBDR), an established climate change narrative. CBDR first appeared in the Rio Declaration on Environment and Development, a 1992 UNFCCC document. Principle 7 of the declaration says, "In view of the different contributions to global environmental degradation, States have common but differentiated responsibilities" (Rio Declaration). In other words, every country contributes to climate change, but relative responsibilities vary. A 1995 UNFCCC conference further developed the idea into a guide for mitigation efforts, saying, "the developed country Parties should take the lead in combatting climate change and the adverse effects thereof" (Framework Convention on Climate Change). Subsequent UNFCCC mitigation policies have invoked CBDR to establish country specific expectations that correspond to their differentiated responsibilities (Harris 34). Specifically, developed countries have extended varying degrees of financial and technological support to developing countries in UNFCCC agreements (Bushey 8).

The Yasuní-ITT Initiative catapulted the CBDR narrative - originally conceived as a guide for mitigation expectations and international cooperation - into a new role to justify Correa's demands for financial compensation. Correa demanded "compensation for the damages caused by the out of proportion amount of historical and current emission of greenhouse gases by industrialized countries" (Correa, "Speech of the President" 2). With this request, Correa appealed to CBDR in an accusatory and aggressive manner generally absent from diplomatic UNFCCC negotiations. While most developed countries have accepted their disproportionate responsibility and burden in regards to climate change, Correa's somewhat tactless application of CBDR likely 
deterred some potential supporters and may have precipitated responses characterizing the initiative as "rain forest for ransom" (Walsh). The aggressive application of CBDR alienated many potential supporters of Correa's campaign and converted a collaborative concept into a combative tool.

Regardless of Correa's methods, his appeal to the CBDR narrative critiqued capitalism and sought to create a universal mindset to approach climate change. By singling out "industrialized countries" and noting that "there are countries that pollute a lot more, there are sectors that pollute a lot more," Correa implicitly critiqued capitalism (Correa, "Speech of the President" 2; Correa, "La Iniciativa Yasuní-ITT" 8). Correa's critique of capitalism targeted the "individualist logic" it employs and, in accordance with the ideals of CBDR, instead asked that the global community accept "joint responsibility" and support the Yasuní-ITT Initiative (Correa, "La Iniciativa Yasuní-ITT” 12; 19). With his calls for joint responsibility, Correa invoked CBDR to elevate climate change mitigation - and his initiative specifically - above the fray of global relations in the interest of "a sustainable future for all" (Correa, "La Iniciativa Yasuní-ITT" 5). Correa's attempt to create a universal mindset with a global goal represented a challenge to the capitalist value of self-interest.

\section{RECONCEPTUALIZATION OF VALUE}

The Yasuní-ITT Initiative also called for a reconceptualization of value. In his 2007 proposal to the UN, Correa explained that the Yasuní-ITT Initiative sought "to transform the old conceptions of the economy and the concept of value" (Correa, "Speech of the President" 3 ). Economic value, in large part, is based on "on what people want - their preferences" (Basic Concepts). Therefore, Correa's attempt to redefine value, at its core, demanded a change in global priorities. Ecuador's proposal to sacrifice half of the monetary value of its oil, instead valuing ecological and environmental wellbeing, modeled this ideological shift. This narrative interacted with Correa's discussion of Buen Vivir and the Kyoto Protocol, and it evolved immensely during the six-year campaign.

Correa's attempt to redefine value drew inspiration from the Buen Vivir movement in Latin America. Buen Vivir, or "Living Well," is "a development concept...that attempts to incorporate the perspectives and views of indigenous peoples" (Cunningham 89). The concept implies living in harmony with "Mother Earth's cycles, with cosmic cycles, with history's cycles, with all life's cycles, and in complementary balance with all forms of existence," and it is frequently framed simply as a "pro-Mother Earth" movement (Cunningham 92; Jaramillo 61). Buen Vivir has recently been incorporated into constitutional reforms in Ecuador and Bolivia, and the movement has a growing presence in Colombia and Peru as well (Jaramillo 61). A key aspect of Buen Vivir is its criticism of capitalism as a major contributor to the destruction of the planet (Jaramillo 62). Alberto Acosta, the former Ecuadorian Minister of Energy and one author of the Yasuní-ITT Initiative, wrote that Buen Vivir is "a distinct alternative to capitalist logic" (Acosta 3).

Buen Vivir's incorporation into the Yasuní-ITT Initiative demanded a shift away from capitalist conceptions of value. Correa rarely referred explicitly to the Buen Vivir movement, but 
in one public speech he characterized the Yasuní-ITT Initiative as a step towards “our ancestor's concept, Buen Vivir, satisfying needs and rights, but living in harmony with nature, with other humans being" (Correa, "La Iniciativa Yasuní” 12). Harmony - a fundamental concept in the Buen Vivir paradigm - was incorporated into Correa's speeches for the duration of the Yasuní-ITT Initiative. Correa's invocation of harmony and Buen Vivir can be traced back to criticisms of capitalism, but Correa also offered his own explicit critique. He said the Yasuní-ITT initiative "proposes a change from economic logic, from individualist logic, to a logic very difficult to achieve in these times, of justice" (Correa, "La Iniciativa Yasuní" 12). Replacing economic logic with justice required a reconceptualization of value, among other attitude changes. Correa asked the global community to value "environmental goods...that generate great value, are a great benefit to humanity" (Correa, "La Iniciativa Yasuní-ITT” 11). By challenging the capitalist ideal of value and alternatively asking the global community to compensate environmental wellbeing, Correa firmly situated his initiative as a product and representation of the Buen Vivir movement.

Correa's attempt to redefine the capitalist ideal of value was initially accompanied by a criticism of the Kyoto Protocol. Early in the Yasuní-ITT campaign, Correa called the flexible mechanisms of the Kyoto Protocol "absurd" and specifically critiqued carbon markets, saying they "give countries incentives to cut their forests, sell the wood and then receive compensation to plant again" (Correa, "La Iniciativa Yasuní-ITT" 9). The Yasuní-ITT Initiative was originally framed as a moral alternative to the problematic Kyoto Protocol, instead asking the global community to work outside of capitalist inspired carbon markets to prevent emissions in the first place. As a "Post-Kyoto" option, it required a reconceptualization of value to rationalize financial compensation for inaction (Martínez). Correa argued that his proposal was, in the end, a measure to reduce emissions, equivalent to the Kyoto Protocol. However, the Kyoto Protocol lacked the "integral concept" of "Net Emissions Avoided," instead recognizing only positive emissions (Correa, "La Iniciativa Yasuní-ITT 10). This argument reveals the key assumption in Correa's attempt to redefine value. In assigning value to environmental and ecological wellbeing, Correa asked that inaction - avoided emissions and avoided ecological destruction - receive the same financial recognition as action. The Yasuní-ITT Initiative, as it was initially conceived, stood as a moral alternative to the Kyoto Protocol's limited view.

Correa's criticism of the Kyoto Protocol was contradicted by his government's actions near the end of the campaign in 2012. With little financial support after five years of campaigning, Ecuador sought to enter the carbon market with "Yasuní Guarantee Certificates" as equivalent units to carbon units. This proposal used the same logic of "Net Emissions Avoided" that Correa had advanced early in the campaign, but the argument was transformed from a critique into a plea for inclusion. The European Union Environmental Trading System (EU ETS), the largest global carbon market, denied Ecuador's proposal on the grounds that it would lead to carbon leakage (Del Hierro). Carbon leakage is an increase in carbon dioxide emissions by one country to compensate for emission reductions in another country (IPCC 1028). In the case of the YasuníITT Initiative, the EUETS presumed that Ecuador's reduction in oil extraction would be offset by increases elsewhere that would maintain global oil use at the same levels and lead to no net environmental benefit. 
The evolution of Correa's attitude towards the Kyoto Protocol added complexity to his campaign to redefine value. While his strong criticism of capitalism and carbon markets faded away with his attempt to enter those same markets, Correa's alternative definition of value was consistent. His campaign to place financial value on inaction and environmental wellbeing was a hallmark of the Yasuní-ITT Initiative, perhaps most importantly when appealing to the EU ETS for recognition in carbon markets. Whether Correa's evolution with respect to the Kyoto Protocol was driven by hypocrisy or a desperate desire to fund his initiative, the result holds the same significance. The global community did not respond to Correa's attempts to redefine value and compensate inaction for the sake of environmental wellbeing.

\section{ECUADOR AS MARTYR AND REVOLUTIONARY}

The final narrative identified in the Yasuní-ITT Initiative is Ecuador as martyr and revolutionary. This narrative, like Correa's attempt to redefine value, evolved through the campaign. Correa initially employed this narrative as a strategy to garner international support and build a global mindset, but it eventually transformed into an explanation for the initiative's failure. In parallel with this evolution, Correa shifted his emphasis from martyr to revolutionary.

Throughout the campaign, Correa's presentation of Ecuador as a martyr and revolutionary served to assert Ecuador's agency and foster a universal mindset. Correa frequently emphasized that Ecuador was renouncing its most beneficial option - extracting the oil - and was therefore "the principle contributor" to the initiative's financial goal (Correa, "Discurso Yasuní ITT" 7). Correa and his government characterized the initiative as an "enormous [sacrifice]," "an act of generosity," and "an innovative, forward-looking, revolutionary idea" (Correa, "Speech of the President," 2; Garcés 2; Correa, "Discurso Yasuní ITT” 5). Correa's characterization of Ecuador as a martyr and revolutionary established his country's agency and insisted that the Yasuní-ITT Initiative represented a measured proposal by a generous country, not a desperate plea for charity. Indeed, Correa frequently clarified this important distinction, saying, "We are not asking for charity, we are asking for joint responsibility" (Correa, "La Iniciativa Yasuní-ITT" 19). Further, this narrative attempted to foster a unified universal mindset, similar to Correa's application of CBDR. As presented by Correa and his government, Ecuador's martyrdom was intended to serve as a foundation for similar, but smaller, international contributions. This narrative bolstered the Yasuní-ITT Initiative's underlying, consistent campaign to challenge and overcome capitalist ideals of value and self-interest.

Correa's characterization of Ecuador as martyr and revolutionary eventually evolved into an explanation for the Yasuní-ITT Initiative's failure. In his speech announcing the initiative's defeat, Correa said, "the initiative was ahead of the times, and those responsible for climate change could not or did not want to understand it" and declared, "history will judge us" (Correa, "Anuncio a la Nación" 4). Whether or not Correa's assessment of the initiative's failure was correct, his righteous, superior tone emphasized Ecuador's role as a revolutionary. In fact, Correa's final speech on the Yasuní-ITT Initiative placed the blame for the proposal's failure with the global community that "could not or did not want to understand it" while characterizing Ecuador as a forward-thinking, honorable country unable to convince the world of its benevolence. While 
Ecuador's characterization as martyr and revolutionary initially served to capture global support and cultivate a universal mindset, the narrative eventually transformed into an explanation for the initiative's defeat.

\section{CONCLUSION}

Although the three primary narratives employed in the Yasuní-ITT Initiative - common but differentiated responsibility, a reconceptualization of value, and Ecuador as martyr and revolutionary - challenged capitalist ideals of value and self-interest, the initiative itself worked loosely within the capitalist framework. Ecuador's pursuit of financial compensation in exchange for protection of environmental wellbeing sought to insert an alternative definition of value into the existing capitalist framework. Even while criticizing fundamental aspects of capitalism and its environmental effects, Ecuador attempted to enter capitalist inspired carbon markets. Interestingly, Ecuador's efforts to gain recognition for "Net Emissions Avoided" mirrored the inception of carbon markets when "the market narrative was used to establish a new commodity in carbon reductions" (Liverman 295). The Yasuní-ITT Initiative attempted to create a new commodity - avoided emissions - within the capitalist framework, but the narratives employed in the campaign challenged fundamental aspects of capitalism.

As a case study, the Yasuní-ITT Initiative provides evidence for the seemingly unavoidable role of capitalist inspired market solutions in international climate change mitigation. Erik Swyngedouw writes about the "post-political frame" of climate change, marked by "the perceived inevitability of capitalism and a market economy as the basic organizational structure of the social and economic order, for which there is no alternative" (Swyngedouw 215). Unfortunately, the fate of the Yasuní-ITT Initiative seems to support this analysis. The narratives employed in the initiative - common but unequal responsibility, a reconceptualization of value, and Ecuador as martyr and revolutionary - challenged key characteristics of capitalism and demanded a global ideological shift, but the initiative itself sought to operate within the capitalist system. The global community rejected Ecuador's attempts to redefine value and foster a universal mindset to approach climate change. When it comes to international mitigation efforts, it may indeed be true that "only policies which offer mutual self-interested gains...stand a chance of succeeding" (Pearce 10).

The narratives deployed in the Yasuní-ITT Initiative failed to attract global support, but they nevertheless could serve an important role in climate change mitigation, albeit on a different scale. The Yasuní-ITT Initiative ambitiously called for "a major discursive shift...across local, national and global arenas" (Espinosa 34). It removed place and culture specific concepts like Buen Vivir from their context and asked the global community to embrace their values. It challenged wealthy countries with strong ties to the oil industry to pay for crude oil to be left untouched. In short, the Yasuní-ITT Initiative may simply have been too ambitious. However, its narratives should not be discarded. Instead, the alternative narratives discussed here should be applied on a smaller, local scale to achieve climate change mitigation. The results will likely be less profound than 846 million barrels of crude oil and 407 million tons of carbon dioxide, but progress is progress. 


\section{REFERENCES}

Acosta, Alberto and Esperanza Martínez. El Buen Vivir: una vía para el Desarrollo. Quito: AbyaYala, 2009. Print.

Achtenberg, Emily. Oil Politics in Ecuador: Saving Yasuní, Without Chevron's Blood Money. North American Congress on Latin America. 6 Jan. 2012. Web. 15 Nov. 2014. Print.

“Basic Concepts of Economic Value.” Ecosystem Valuation. n.p, n.d. Web. 10 Dec 2014.

Bushey, Douglas, and Sikina Jinnah. "Evolving Responsibility: The Principle of Common but Differentiated Responsibility in the UNFCCC." Publicist 6 (2010): 1-10. Print.

Cisneros, Paúl. "Gobernanza Ambiental, Conservación y Conflicto en el Parque Nacional Yasuní." La guerra del fuego,. Políticas petroleras y crisis energética en América Latina. Ed. Guillermo Fontaine and Alicia Puyana. Quito: Flasco-Sede, 2008. Print.

Correa, Rafael. “Acto Masivo con Grupos Sociales en el Estado ‘Evo Morales Ayma.” Cochabamba. 3 Oct. 2013. Address.

. “Anuncio a la Nación Iniciativa Yasuní ITT.” Quito. 15 Aug. 2013. Address.

. “Decreto Numbero 74.” 15 Aug. 2013. Quito. Print.

. "Decreto Numero 84.” 17 Aug. 2013. Checa. Print.

. “Discurso Yasuní ITT Ante la ONU.” New York. 23 Sept. 2011. Conference Presentation.

. "La Iniciativa Yasuní-ITT: Cambiando Paradigmas para un Futuro Sustenable.” Río de Janeiro. 20 June 2012. Address.

. "Speech of the President of the Republic of Ecuador Excellency Rafael Correa." High Level Dialogue on Climate Change of the 52 Period of Sessions of the General Assembly of the United Nations. New York. 24 Sept. 2007. Conference Presentation.

Cunningham Kain, Mirna. "Laman Laka: Our Indigenous Path to Self-Determined

Development." Towards an Alternative Development Paradigm: Indigenous Peoples' SelfDetermined Development. Philippines: Tebtebba Foundation, 2011. 89-116. Print.

Del Hierro, Santiago. "Yasuní-ITT” Extra State Craft. n.p, 2012. Web. 10 Dec 2014.

Espinosa, Cristina. "The Riddle of Leaving the Oil in the Soil-Ecuador's Yasuní-ITT Project from a Discourse Perspective." Forest Policy and Economics. 36 (2013): 27-36. Web.

Falconí, Benítez. "La Iniciativia Yasuní ITT es una Gran Senal para la Humanidad.” Ecología Política. 39 (2009): 83-86. Web. 
Falconí, Fander. "El ITT: Prueba de Vida." Íconos: Revista de Ciencias Sociales 38 (2010): 17-20. Web.

Framework Convention on Climate Change, Conference of the Parties. Berlin: United Nations, 6 June 1995. Print.

Forsyth, T. (2008). Political Ecology and the Epistemology of Social Justice. Geoforum, 39(2), 756-764.

Garcés, Lenín Moreno. “Addreses by Mr. Lenín Moreno Garcés, Vice-President of the Republic of Ecuador.” United Nations General Assembly, Sixty-fifth session. New York. 27 Sept. 2010. Conference Presentation.

Gee, Time. “Yasuní: A Cautionary Tale.” New Internationalist. (2014): 38-40. Web.

Harris, Paul G. "Common but Differentiated Responsibility: The Kyoto Protocol and the United States Policy.” NYU Environmental Law Journal 7 (1999): 27-48. Print.

Intergovernmental Panel on Climate Change. Climate Change 2014: Mitigation of Climate Change (WGIII AR5), 2014. Print.

Jaramillo, Efraín. "Mother Earth and 'Living Well.”. Indigenous Affair 10.1-2 (2011): 60-63. Print.

Liverman, Diana M. "Conventions of Climate Change: Constructions of Danger and the Dispossession of the Atmosphere." Journal of Historical Geography 35.2 (2009): 279296. Print.

Martin, Pamela L. "Global Governance from the Amazon: Leaving Oil Underground in Yasuní National Park, Ecuador." Global Environmental Politics 11.4 (2011): 22-42. Web.

Martínez, Esperanza. De Kyoto a Quito. 9 May 2007. Web. 15 Nov. 2014.

Martinez, Joan. "Keep Oil in the Ground: Yasuní in Ecuador.” Economic and Political Weekly 42.42 (2007): 4227-4228. Web.

McAvoy, Esme. "Oil or life? Ecuador's stark choice." New Internationalist 441 (2011): 26-31. Web.

Pearce, David and Dominic Moran. The Economic Value of Biodiversity. London: Earthscan, 1994. Print.

Permanent Forum on Indigenous Issues New York 1O-3O April 201O. United Nations Economic and Social Council, 16 Mar. 2010. Print.

Quiñónez, Iván Narváez. Petróleo y Poder: el Colapso de un Lugar Singular: Yasuní. Quito: Flacso-Sede, 2009. Print. 
Ramírez, René. "La transición Ecuatoriana Hacia el Buen Vivir." Sumak (2010). Web.

Rio Declaration on Environment and Development. Rio de Janeiro: United Nations Conference on Climate Change, 14 June 1992. Print.

Swyngedouw, Erik. "Apocalypse forever? Post-political populism and the Spectre of Climate Change." Theory, Culture \& Society 27.2-3 (2010): 213-232. Print.

Walsh, Bryan. "Rain Forest for Ransom.” Time 2 Feb. 2012: 36-39. Web. 